\title{
Be Too Kind to a Woman, She'll Feel Incompetent: Benevolent Sexism Shifts Self-construal and Autobiographical Memories Toward Incompetence
}

\author{
Muriel Dumont • Marie Sarlet • Benoit Dardenne
}

Published online: 23 December 2008

(C) Springer Science + Business Media, LLC 2008

\begin{abstract}
The present study investigated how benevolent (BS) and hostile sexism (HS) shift women's self-construal and autobiographical memory. Belgian undergraduates (only women, $N=45$, mean age $=21.8$ ) were confronted either by BS, HS or neutral comments in the context of a job interview. After performing a cognitive task, participants reported the intrusive thoughts that came to their mind during the task. Later, autobiographical memory for self-incompetence was assessed. Performance response latencies were slower after BS than HS. Also, BS generated more disturbing mental intrusions related to the idea of being incompetent than HS. Autobiographical memory similarly indicated greater access for incompetence after BS. Although HS was more aggressive in tone, it did not shift women's self-construal and autobiographical memories toward incompetence.
\end{abstract}

Keywords Sexism · Self-construal · Incompetence · Autobiographical memory $\cdot$ Performance

This research was supported by an incentive grant I-06/07 to Benoit Dardenne and by a grant SFR 2007 to Marie Sarlet, both from the University of Liège.

M. Dumont $\cdot$ M. Sarlet $\cdot$ B. Dardenne $(\bowtie)$

Department of Cognitive Sciences, University of Liège,

Boulevard du Rectorat, 5 (B32),

4000 Liège, Belgium

e-mail: b.dardenne@ulg.ac.be

M. Sarlet

Fonds National de la Recherche Scientifique (FRS-FNRS),

Brussels, Belgium

\section{Introduction}

Ambivalent sexism theory, as stated by Glick and Fiske (1996, 2001), proposes that two components of sexism, hostility and benevolence, are strongly interrelated but can nevertheless be conceptually distinguished. Hostile sexism (HS) is an obviously antagonistic negative attitude toward women that casts them as seeking to gain control over men. HS is indeed directed at women who challenge men's power by questioning traditional beliefs (e.g., by expressing feminist attitudes), seeking a prestigious or powerful role (e.g., pursuing a high status job), or using men's sexual attraction to them to gain influence over them (e.g., by being a "temptress"). Benevolent sexism (BS), on the other hand, is a more positive attitude toward women that portrays them as warm but suggests that they are less competent than men. BS idealizes women and suggests that they ought to be placed on a pedestal, but only if they conform to the traditional roles men assign them and do not challenge men's authority (Glick et al. 1997). Although there are some variations, HS and BS are pervasive across cultures and nations, supporting the idea that they originate in social and biological factors common among human groups (Glick et al. 2000). Much of the research on sexism is done in the United-States, but many of the consequences of sexism are the same in other countries around the world. "Equal pay for equal work" is one of the European Union's founding principles enshrined in the Treaty of Rome in 1957. Despite this, the figures reveal a continuing pay gap of $15 \%$ on average between male and female workers. This pay gap generally reflects the inequalities that tradition, social norms, and stereotypes bring to bear on women in orienting their education, occupation, and participation in the labor market. Belgian women do not escape from this reality. 
Although benevolence is better accepted within the private than the occupational sphere (Moya et al. 2007), such an attitude has been shown to impact women's cognitive capacities when performance is tested in a work context. Moreover, Dardenne et al. (2007) provided evidence that women confronted by BS reported greater intrusive thoughts and worries about their abilities to perform well than women confronted by HS or neutral comments. The aim of the present study is to extend Dardenne et al.'s (2007) results in several ways. First, we aim at examining whether women's worries about their ability to perform the task also affect their self-construal such that BS leads to greater dispositional attribution of being incompetent than HS. Second, we propose that suppression efforts would be devoted to suppress such intrusive thoughts. Third, and most importantly, we aim at examining whether BS contaminates self-related cognitive processes such as autobiographical memory. That is, we propose that BS biases autobiographical memory such that incompetence-related instances of behavior are more accessible to women than when they are confronted by HS or neutral comments.

\section{Influences of BS and HS on Women}

In a recent series of studies, Dardenne et al. (2007) demonstrated that BS more than HS impaired women's cognitive performance and increased their worries in an occupational context. Specifically, the studies made salient the context of job interviews and selection testing, and conveyed BS, HS, or non-sexist attitudes through the recruiter's comments. Then, female participants performed a (selection) test. BS theoretically encompasses three subcomponents: paternalism (the belief that men should protect and provide for the women on whom they depend), complementary gender differentiation (the belief that women are the better gender, but only in ways that suit conventional gender roles), and intimate heterosexuality (the belief that men can achieve true happiness in life only when involved in romantic relationships with women), which contribute to controlling women by offering them the deal to conform to a traditional, subordinate role in order to be protected and cherished. Dardenne et al. (2007) provided evidence that both the paternalist and the complementary gender differentiation components of BS were negative for women's cognitive performance in tasks involving working memory (i.e., problem-solving task and Reading Span test). Moreover, consistent with Barreto and Ellemers (2005), Dardenne et al. (2007) showed that BS was subtle enough not to be identified as sexism, but was nevertheless experienced as quite unpleasant and eliciting intrusive thoughts. Such thoughts referred to preoccupations with the task, general self-doubts, and low performance self-esteem.
In contrast, hostile sexism did not generate intrusive thoughts and did not alter women's capacity to perform well. Note that if participants in Dardenne et al. (2007)'s studies were pretty much preoccupied with the complexity of the task, those in Barreto and Ellemers (2005)'s study could hardly be suspected to suffer from a cognitive load given the simplicity of the task at hand. In that study, participants had nothing else to do than answering a short questionnaire. Overall, this is consistent with the idea that BS more than HS activates the idea that women are incompetent.

Dumont and Dardenne (2008) also provided indirect support for such a hypothesis. In fact, they examined conditions under which the negative impact of BS on women's cognitive capacities was avoidable. Specifically, although Dumont and Dardenne (2008) did not provide evidence that incompetence-related thoughts have been elicited by BS, they showed that providing women with positive feedback on their aptitude to perform the task at hand led women who were confronted by BS to avoid any decrease in their actual performance. However, several processes could underlie the positive impact of providing positive feedback on later performance. One might consider, for instance, that the positive feedback provides an opportunity for self-affirmation that lowered the contextual stress and evaluation threat. Alternatively, assuming that intrusive thoughts elicited by BS usually impair performance, it might be that being provided with positive feedback is refuting the idea that women are incompetent, thereby preventing performance decrease. Complementary to this research, we thus more deeply investigate the BS consequences and propose that BS not only affects intrusive thoughts with respect to a contextual failure (rather than any other process) but also shifts women's self-construal such that they feel more incompetent than when confronted by HS.

Intrusive thoughts and ideas about being incompetent might be quite uncomfortable. Therefore, we hypothesize that women confronted by BS certainly use strategies to fight against the intrusive thoughts they suffer. Several processes could be evoked to manage unwanted thoughts. For example, one strategy consists in actively trying to suppress the unwanted thoughts (e.g., "I should stop thinking about X"). Another strategy consists in trying to get concentrated or focused on something else than the unwanted thoughts such as, of course, the main task at hand (e.g., "I should concentrate on X"). Most of the time, people likely use both these strategies simultaneously in order to get rid of unwanted thoughts (Wegner and Erber 1992; Wegner et al. 1987). Importantly, when the task at hand requires substantive cognitive resources, concentration attempts may be elicited even when there are no unwanted thoughts to deal with, whereas suppression 
attempts should be solicited only when thoughts are unwanted. Therefore, we expect participants in all conditions to attempt to concentrate on the task, whereas BS more than HS should elicit attempts at thought suppression. Greater suppression attempts after BS, and a positive correlation between suppression efforts and intrusive thoughts, would further support the idea that the intrusive thoughts women experience when confronted to that type of sexism are experienced as uncomfortable.

Importantly, cognitive processes related to the self are likely to be affected by BS too. For instance, autobiographical memory is definitely strongly dependent on selfconstrual. Autobiographical memory is devoted to the construction and maintenance of the self-construal and identity (Robinson, 1992) and therefore refers to the storage and retrieval of information about the self (Baddeley, 1992). Bias in autobiographical memory has lots of implications for how people think of themselves and esteem themselves. Moreover, this certainly is a determinant for people's life and career goals. Therefore, bias in autobiographical memory is especially interesting to examine in the context of sexism's influence. We propose that biased access to autobiographical memory might well co-occur with shifts in self-construal. Specifically, if BS leads women's self-construal to be associated to incompetence, access to autobiographical memories for women's own incompetence might be facilitated along similar lines.

\section{Overview}

The present study examines the impact of sexism on women's self-construal and autobiographical memory. Extending earlier studies showing that women confronted by BS rather than HS experience intrusive thoughts about performing badly (Dardenne et al. 2007), we propose that BS also specifically leads women to think of themselves as being incompetent while performing the task and to attempt suppressing such thoughts. Besides, suppression attempts might also ironically reinforce thoughts about being incompetent (Wegner and Erber 1992; Wegner et al. 1987). Therefore, these two measures should be specifically correlated when BS is salient. After being confronted by BS, HS, or neutral comments, participants perform a substantive task as in Dardenne et al. (2007). The task is presented as a performance task on the basis of which a hiring decision will be taken. Next, we assess the extent to which women experience intrusive thoughts related to the idea that they are incompetent while performing the task together with suppression and concentration self-injunctions. In addition, thoughts related to sexism are assessed as a manipulation check with the hypothesis that ideas about sexism are greater after HS than in any other condition. Finally, autobiographical memory is assessed. Our hypothesis is that BS leads to greater access than either HS or neutral comments to autobiographical memories for situations in which women have felt themselves incompetent. Since participants perform a cognitive task, we also expect to replicate Dardenne et al. (2007) such that BS would be worse for women's performance than HS or neutral comments.

\section{Method}

\section{Participants}

The participants were 45 women undergraduates (mean age $=$ $21.8, \mathrm{SD}=1.65 ; N=14$ in the no-sexism condition, 16 in the BS condition, and 15 in the HS condition) right-handed and native French speakers. Participants were approached in different places on the campus. If they agreed to participate, they were invited to follow the female experimenter to the laboratory. Informed consent was obtained in a manner approved by the Ethics Committee at the University of Liège.

\section{Material and Procedure}

Participants were told that they were about to participate to two distinct short studies. The first study was said to investigate how people react to various job application contexts. The second study was said to be concerned with autobiographical memory.

\section{Manipulation}

The study was presented as training for job interviews (all materials are available on request, in French as well as translated in English). Participants were randomly assigned to one of three conditions of sexism (HS vs. BS vs. No sexism) before performing a Reading Span Test (RST) presented as the selection test. All instructions and the test were presented in written format on a computer screen. Participants were told that a chemical factory was offering new jobs. The job for which they supposedly applied was described as requiring typically feminine qualities. That is, the job description matched jobs with which women would usually feel comfortable. In all conditions, participants were informed that the job required communication and social skills as well as work-team orientation. Specifically, the abilities mentioned as required for the job were "sensitive to clients' needs," "cooperative orientation," "good social abilities," and "attentive to clients." Also, the recruiting procedure was said to include performing a test (i.e. RST) alleged to be well known and frequently used within job recruitment procedures. 
The hostile and benevolent sexist comments included as the manipulation conveyed explicit expressions of the corresponding attitudes measured by the Ambivalent Sexism Inventory (Glick and Fiske 1996; see Dardenne et al. 2006, for a French validation). We manipulated BS through its complementary gender differentiation component. In all conditions, it was explained that hiring women would be a good thing for the organization. In the BS condition, additional comments central to the manipulation were as follows: "Women who would be hired would work as much with men as women and this should not be a problem because everybody is well aware of the importance of hiring women in our organization. Indeed, all think that the presence of women, who are more cultured and wellgroomed than men, would allow the organization to benefit from their morality and good taste, whereas these aspects usually lack in environments where only men work".

In the HS condition, additional comments central to the manipulation were as follows: "Women who would be hired would work as much with men as women and this should not be a problem because everybody is well aware of the importance of hiring women in our organization, even if women always look for special favors and get easily offended by trivial remarks. It is true that women often exaggerate the problems they face in organizations simply to get power and control over men".

In the no-sexism condition, the comments contained nothing more than the job description and the introductory comment: "Women who would be hired would work as much with men as women and this should not be a problem because everybody is well aware of the importance of hiring women in our organization."

\section{Dependent Variables}

Performance task The RST was composed of ten blocks of trials. Within each block, participants were presented with five sentences that they had to read silently, make a decision about whether the sentence was grammatically correct or not and remember the last word of the sentence. In order to ascertain that all participants used the same strategy to perform the task, the instructions mentioned that taking the grammatical decision first and then memorizing the last word of the sentence has been shown to be the most efficient strategy. The five sentences were always followed by a recognition screen (see Fig. 1) providing the first or last letter of the words that were to be remembered as memory cues. Half of the sentences were grammatically correct whereas the other half were not. Each sentence was presented for $10 \mathrm{~s}$, whether or not an answer was provided. Similarly, half of the recognition screens corresponded to the words' letters that had been presented just before whereas the other half did not. Recognition screens

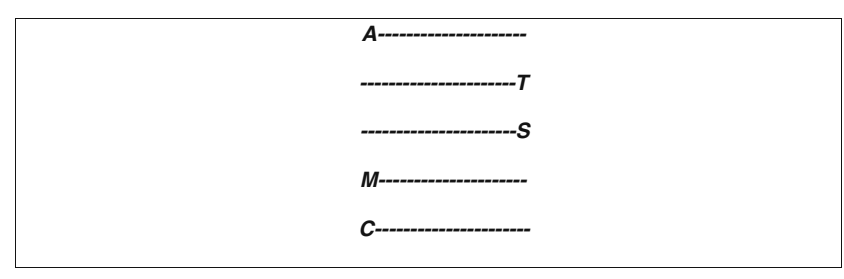

Fig. 1 Example of a recognition screen.

however were presented until an answer was provided. In all conditions, participants made a keyboard response (yes/ no) whenever providing an answer (grammatical decision or recognition answer). Response latencies and accuracy of the responses were recorded.

Perception of sexism, incompetence-related intrusive thoughts, and self-injunctions After performing the task, participants filled out a questionnaire about the thoughts that might have occurred while they were performing the task. Specifically, they were asked to rate how much that specific thought had come to their mind during the test. Because of this formulation, each item was at the present time. Items were anchored from 1 (never came to my mind) to 9 (came to my mind very often). Intrusive thoughts referred to the feeling of being incompetent ("I feel silly"; "I feel incompetent"; "I feel that I'm not performing well"; "Others are surely faster than I am"; "Others surely perform better than I do"; "I'll never achieve it"; $\alpha=.90$ ), to suppression injunctions ("I must stop thinking that I've made a mistake"; "I must stop thinking that I must repeat the words again and again"; "I must stop thinking that I've forgotten the words"; $\alpha=.85$ ), to concentration injunctions ("I must be organized"; "I must do better"; "I must memorize all the words"; "I must not be wrong"; "I must not forget the words"; $\alpha=.82$ ), and to perception of sexism and the recruiter's considerations about women ("I have the feeling that one wants to trap me in the role of a woman"; "I feel ill at ease with what they think of women"; "I disagree with these considerations about women"; $\alpha=.61$ ). This last measure also serves as a manipulation check.

Autobiographical memory for being incompetent Before being debriefed, participants were asked to contribute to a second very short study investigating autobiographical memory. They were asked to choose one out of three cards in order to know what kind of autobiographical memories they would have to retrieve. Actually all three cards indicated that they had to retrieve as many memories as possible for situations in which they have felt "silly, incompetent, or less smart than others". Participants were then asked to write down a single keyword on one line for each of the retrieved situations. Because every single word written down by the participant was considered to be related to an instance of incompetence by the participant 
herself, one of us simply counted the number of words as an index of autobiographical memory for being incompetent (with coder blind to conditions).

After completing the task, participants were fully debriefed and thanked for their participation. Special care was directed to communicating the point of the study, given that some participants may have felt bad, especially in case of strong feelings of incompetence.

\section{Results}

Contrast analyses were used to test our specific predictions. These analyses are the appropriate ones because they focus on our specific hypotheses and use appropriate degree of freedom.

\section{Performance and Response Latencies}

Contrast analyses were used to analyze the level of accuracy of the grammatical decisions and cued recall as well as response latencies on correctly answered items. With the first contrast we compared BS (coded: 2) to the two other conditions (HS and neutral condition were coded -1 ). In order to ascertain no differences between the two other conditions, the second contrast had HS (coded: 1) compared to the condition where no sexism was expressed (coded: -1 ). One, the other, or both measures might be affected by BS more negatively than by HS or neutral comments. However, given the difficulty of the task and the time constraints imposed, we expect response latencies rather than accuracy to be sensitive to our manipulation.

Analyses revealed no significant contrast on the accuracy of grammatical decisions (see Table 1). BS led to a similar level of accuracy as the two other conditions, $\beta=$ $-.18, p>.22$, which did not differ from one another, $\beta=.14$, $p>$.36. Accuracy of cued recall also did not lead to significant differences between sexism conditions (see
Table 1). BS led to a similar level of accuracy as the two other conditions, $\beta=-.24, p>.12$, which did not differ from one another, $\beta=-.02, p>.87$. Grammatical decisions led to a good percentage of correct answers (Mean=85\%; SD= $8.82)$, whereas correct cued recall was moderate (Mean= $61 \%$; $\mathrm{SD}=16.92$ ). This (lack of) result is not surprising given the time limit constraint imposed on the task.

Importantly, and as predicted, analysis of the response latencies to the correct grammatical decisions revealed a significant effect of sexism. As can be seen on Table 1, participants confronted by BS comments manifested slower decision latencies than those confronted by $\mathrm{HS}$ or no sexism, $\beta=.33, p<.03$. HS, however, led to a similar performance as the condition in which no sexism was expressed, $\beta=-.23, p>.11$. Response latencies to correct cued recall items revealed a similar pattern (see Table 1). Participants confronted by BS manifested slower recall latencies than those confronted by HS or no sexism, $\beta=.34$, $p<.03$. HS led to a similar performance as the condition in which no sexism was expressed, $\beta=-.07, p>.63$.

Perception of Sexism, Incompetence-related Intrusive Thoughts, and Self-injunctions

Barreto and Ellemers (2005) as well as Dardenne et al. (2007) showed that BS was less easily identified as sexism than HS. Therefore, our hypothesis is that thoughts referring to sexism and to the recruiter's considerations about women should be greater after HS than in any other condition. This measure was thus examined through contrast analyses with the first contrast comparing HS (coded: 2) to the two other conditions (BS and neutral condition were coded -1 ), and a second contrast where BS (coded: 1) was compared to no sexism (coded: -1 ). Consistent with our prediction, women confronted by HS reported the highest preoccupation with the recruiters' considerations about women, $\beta=.47, p<.001$. Participants confronted by $\mathrm{BS}$ also were more preoccupied with the

Table 1 Descriptive statistics for accuracy/response latencies of grammatical decisions/cued recognition and autobiographical memories.

\begin{tabular}{|c|c|c|c|c|c|c|}
\hline & \multicolumn{2}{|c|}{ Benevolent sexism } & \multicolumn{2}{|c|}{ Hostile sexism } & \multicolumn{2}{|c|}{ No sexism } \\
\hline & Mean & SD & Mean & SD & Mean & SD \\
\hline \multicolumn{7}{|l|}{ Accuracy (\%) } \\
\hline Grammatical decisions & 82.87 & 7.12 & 87.73 & 9.68 & 84.71 & 9.47 \\
\hline Recognition & 56.25 & 16.68 & 64.00 & 17.65 & 65.00 & 16.05 \\
\hline \multicolumn{7}{|l|}{ Response latencies (ms) } \\
\hline Grammatical decisions & 6,067 & 856 & 5,057 & 1,127 & 5,642 & 942 \\
\hline Recognition & 6,852 & 2,610 & 5,008 & 1,680 & 5,406 & 2,202 \\
\hline \multicolumn{7}{|c|}{ Number of autobiographical memories for being incompetent } \\
\hline & 11.19 & 5.38 & 5.67 & 2.47 & 7.14 & 3.16 \\
\hline
\end{tabular}

Accuracy is indicated as the percentage of correct answers. Response latencies for correct answers are indicated in milliseconds 
recruiters' considerations about women than participants confronted by no sexism, $\beta=.31, p<.03$ (see Table 2).

In line with our hypotheses, incompetence-related intrusive thoughts and self-injunctions were analyzed using contrast analyses with the first contrast comparing BS (coded: 2) to the two other conditions (HS and no sexism were coded -1) and a second contrast comparing HS (coded: 1) to no sexism (coded: -1 ). As predicted, intrusive thoughts about feeling incompetent revealed significantly greater when BS was expressed to participants than when HS and neutral comments were communicated through the recruiters' discourse, $\beta=.46, p<.001$ (see Table 2). The latter two conditions did not differ from one another, $\beta=-.02, p>.87$. Suppression self-injunctions also revealed significantly greater when women were confronted by BS rather than by HS or no sexism, $\beta=.39, p<.008$. The latter two conditions did not differ from one another, $\beta=.05$, $p>$.70. As expected, concentration self-injunctions were relatively recurrent but analogous in all conditions (all $\beta \mathrm{s}<.18, n s)$.

We proposed that intrusive thoughts related to the idea of being incompetent generate suppression self-injunctions. Therefore, these two variables should be strongly correlated but only when sufficient intrusive thoughts are present, that is, when women are confronted by BS rather than by HS or neutral comments. In order to examine that hypothesis, correlations were computed separately for BS and the two other conditions. As expected, intrusive thoughts related to the idea of being incompetent and suppression selfinjunctions were not correlated when women were confronted by HS or neutral comments, $r(29)=-.06, p>$.75. In contrast, these two variables were strongly related to one another in the BS condition, $r(16)=.69, p<.003$.

Our pattern of data might suggest that intrusive thoughts are responsible for the slowing down observed in response latencies, as it was the case for accuracy in Dardenne et al. (2007). However, it would be very surprising to obtain such a mediation path because of the measures that we used to collect the data. Indeed, intrusive thoughts were measured after participants were confronted to the performance task and could only be apprehended globally. That is, such a global measure of intrusive thoughts does not allow knowing precisely "when" the intrusive thought occurred to mind. Therefore, the measure do not allow to know to which item the participant was confronting and whether response latency to that item was slowing down when the intrusive thought occurred. Consistent with this reasoning, the analysis revealed that globally measured intrusive thoughts were not significantly correlated with response latencies of neither grammatical decisions nor recognition. To our view, response latency for a specific item is likely slowed down at the very moment an unwanted thought intrudes in mind. Therefore, the test for mediation would require recording response latency and intrusive thoughts on line.

Autobiographical Memories for Being Incompetent

As stated in the Introduction, we predicted that BS leads to greater access than either HS or neutral comments to autobiographical memories for situations in which women have felt themselves incompetent. The number of autobiographical memories for situations in which participants have felt "silly, incompetent, or less smart than others" in the past was analyzed using contrast analyses, with the first contrast comparing BS (coded: 2) to the two other conditions (HS and neutral condition were coded -1 ), and a second contrast comparing HS (coded: 1) to the neutral condition (coded: -1 ). As can be seen in Table 1 , results showed that BS comments led to greater accessibility of memories for being incompetent than HS or neutral comments, $\beta=.51, p<.001$. The latter two conditions did not differ from one another, $\beta=-.13, p>.31$ (see Table 1).

\section{Discussion}

The aim of the present study was to examine the impact of sexism on women's self-construal and autobiographical memory. Dardenne et al. (2007) proposed that women doubted their abilities to perform the task only when BS was expressed because it suggested women's inferiority.

Table 2 Descriptive statistics for perception of sexism, incompetence-related intrusive thoughts, and self-injunctions as a function of the type of sexism communicated.

\begin{tabular}{|c|c|c|c|c|c|c|}
\hline & \multicolumn{2}{|c|}{ Benevolent sexism } & \multicolumn{2}{|c|}{ Hostile sexism } & \multicolumn{2}{|c|}{ No sexism } \\
\hline & Mean & SD & Mean & SD & Mean & SD \\
\hline Perception of sexism & 2.06 & 1.23 & 2.84 & 1.41 & 1.10 & .28 \\
\hline Incompetence & 5.18 & 2.12 & 3.21 & 1.81 & 3.32 & 1.33 \\
\hline Suppression injunctions & 3.98 & 2.36 & 2.44 & 2.03 & 2.17 & 1.12 \\
\hline Concentration injunctions & 5.75 & 1.80 & 5.51 & 2.00 & 4.73 & 1.73 \\
\hline
\end{tabular}

Scales ranged from 1 (never came to my mind) to 9 (came to my mind very often) 
Consistent with Dardenne et al. (2007), we showed that women confronted by BS actually experienced greater intrusive thoughts referring to the idea of being incompetent while performing a cognitive task than women confronted by HS or neutral comments. This provides additional evidence that BS actually activates the idea of women being incompetent. In addition, extending such initial findings, we also showed that access to autobiographical memories for being incompetent was facilitated by BS as compared to HS and neutral comments.

In line with our hypothesis, we thus provided consistent data indicating that BS shifts both women's self-construal and their autobiographical memory such that women think of themselves as being incompetent. By focusing on positive stereotypical characteristics of women, BS thus implicitly conveys the idea of their incompetence and that idea colored women's thoughts and affected their autobiographical memory. As an indication that thoughts related to incompetence of the self were disturbing, thought suppression attempts (i.e. self-injunctions) were greater after BS than HS or neutral comments. Moreover, intrusive thoughts related to incompetence of the self and suppression selfinjunctions were positively correlated only when women were confronted by BS. In contrast, consistent with the idea that BS is subtler and less easily detected as HS (Barreto and Ellemers 2005; Dardenne et al. 2007), thoughts referring to sexism were greater after HS than BS. In the present study as well as in Dardenne et al. (2007), women could have suffered from cognitive load. They had to decide grammar and memorize the last word or they had to solve a relatively complex problem. However, the result that women did not detect BS as sexism (found in Barreto and Ellemers 2005) could hardly be attributed to cognitive load women would have suffered.

Therefore, cognitive load does not seem a necessary condition for BS not being recognized as a form of prejudice. However, as indicated by more sexism-related thoughts after BS than after neutral comments, women also felt somewhat ill at ease when confronted by a subtle form of sexism. One should note that the neutral comments condition, that is, what we termed the no-sexism condition, led to virtually no detection of sexism at all (with a mean detection of 1.1 on a scale from 1 to 9). In other words, one could hardly interpret the basic scenario of the study as creating a base-line sexist environment. At least, the basic scenario does not seem to make gender stereotypes salient in the eyes of our female participants. However, it could be possible that the basic scenario we used in the present experiment is a necessary but not sufficient condition for the negative effects of BS. Along the same line, the basic scenario could have somehow "primed" a sexist context that could explain in part the lack of negative effects of HS. Further work is needed to resolve this issue and to determine whether cognitive load could explain that BS is less likely to be recognized as sexism than HS.

Although examining the impact of sexism on performance was not a main goal of our study, analyses replicated Dardenne et al. (2007) results of BS being worse for women performance than HS or neutral comments. However, response latencies rather than accuracy revealed sensitive to sexism. Indeed, contrary to Dardenne et al. (2007), the performance task we used was displayed on a computer screen and designed such that the time of item presentation was fixed which led to an important time constraint. Actually, Dardenne et al. (2007) also had a time constraint since the time allowed to perform the whole task was fixed and short enough not to allow participants to perform all the items. Therefore, although their participants had the opportunity to process the information and perform each item at their own pace, performance referred to the number of items correctly performed "within the period of time allowed to perform the task". That is, slow participants certainly completed fewer items (even if correctly answered) than faster participants, which resulted in a lower performance score. In sum thus, in Dardenne et al. (2007) as well as in our study, response latencies were a critical factor. It is thus not surprising that in our design response latencies rather than accuracy revealed sensitive to the sexism manipulation.

The mindset created under the cover of inoffensive introductory benevolent remarks certainly has important consequences. Several theories stress the role of benevolent stereotypes and "nice" ideologies in leading members of disadvantaged groups to justify the status quo. Clearly, benevolent statements elicited some negative ideas about women, who were suggested to be relatively incompetent. Shifting self-construal along such ideas and internalizing incompetence certainly contributes to women accepting and/or legitimizing their (personal) subordinated status (Haines and Jost 2000; Rudman and Heppen 2003). On one hand, performing badly certainly contributes to the prevailing feeling that their subordinate position and gender inequality are legitimate. On the other hand, internalization of being incompetent as reflected through incompetence coloring women's self-construal certainly also contributes to their acceptance of gender-based inequality. Moreover, as incompetence is thought to be dispositional and stable (selfrelated) rather than contextual and unstable (contextdependant), shift in women's self-construal likely also supports their submissive attitude. Biased autobiographical memory also comes to confirm and support the idea that the incompetence is and has always been a self-defining attribute.

Certainly, holding a negative view of the self and, specifically, feeling incompetent should contribute to women considering that they do not deserve more than 
the subordinate positions they have. That is, viewing themselves as incompetent certainly contributes to women not challenging men's privileges and authority and to accepting "things as they are". Negative self-views may affect a variety of domains in life and definitely domains where BS is encountered. If held by female students at an age to decide on career choices, for instance, incompetent views of themselves might lead women to opt for low rather than high status jobs. Women may orient their career choices, for instance, because of recurrent feelings of being incompetent in some specific domains, and BS expressed to them in such domains likely contributes to that feeling. Being too kind to women, especially in domains where they are not welcome, might thus be a very subtle tool men may (intentionally or not) use to press women to avoid such domains. That is, such a view of the self likely has detrimental consequences that do not stop at a single contextual episode but rather expand to the societal gender equilibrium. At a more individual level, further research should be devoted to examine the influence of shift in selfviews on mood and depressive ruminations, which might have heavy consequences for women's health.

Glick and Fiske (1996, 2001; Glick et al. 2000) have constantly argued that benevolent sexism and the "women are wonderful" effect documented by Eagly and Mladinic $(1989,1993)$ serve to increase support for the system of gender inequality. According to ambivalent sexism theory (e.g., Glick and Fiske 2001), social dominance theory (e.g., Sidanius and Pratto 1999), and system justification theory (e.g., Jost and Banaji 1994), high-status groups keep lowstatus groups in the state of subordination through using stereotypes as legitimizing tools. Internalizing stereotypes such that biased access to autobiographical memory and the self-construal include ideas of the self being incompetent is thus certainly one of the paramount features of such tools. Supporting Cose (1993) and Jackman (1994) suggestions that dominant groups favor benevolence toward low-status groups, its influence on autobiographical memory and shifts in self-construal confirm the subtlety and efficiency of such a preference. This is also perfectly consistent with a study by Jost and Kay (2005) demonstrating women's proneness to support the societal system of inequality after being exposed to benevolent stereotypes than either to hostile stereotypes or to favorable but nonstereotypical ideas about women. That is, internalization through self-construal changes may be one of the reasons for such a system justification.

Our results are further fully consistent with Dumont and Dardenne (2008) who provided evidence that the negative consequence of BS on performance was avoidable. Specifically, they confronted women with either BS or HS and provided them with false feedback on their competence in performing a (training) task similar to the main task to be performed. Of course, in the case of positive feedback, any belief in women's own incompetence (assuming they were elicited by BS) is being refuted. Dumont and Dardenne's (2008) results showed that positive feedback led women who were confronted by BS to avoid any decrease in their actual performance. Moreover, provision of positive false feedback reduced the willingness of women who were confronted by BS in accepting the status quo. Results of the present study thus nicely corroborate and extend Dumont and Dardenne's (2008) suggestions.

Our results are also perfectly in line with the literature on the mixed content model of out-group stereotypes which suggests that there is a negative relationship between competence and warmth (Fiske et al. 2002, 2007; Judd et al. 2005; Yzerbyt et al. 2008). This compensation effect goes beyond impression formation of others and out-groups as it can affect the judgment of groups to which the perceivers themselves belong to (Kervyn et al. 2009). In our study, BS relates to and promotes warmth, so it encourages a trade-off with incompetence. When our female participants are the targets of benevolent and warm sexist comments about their gender group, the related idea of incompetence comes together and women appear to behaviorally confirm the lack of competence. Our behavioral observations are thus perfectly in line with judgmental effects reported by the literature on the mixed content model of out-group stereotype.

To conclude, we provided the very first evidence that BS has the power to drive women into internalizing the best justification for gender inequality: incompetence. By shifting women's autobiographical memory and self-construal, BS indeed set the conditions for women to passively accept their own subordination. Although further research is certainly needed to investigate the causal influence of biased memory and shifts in self-construal on other variables and their implications for intergroup relationships, we already can affirm that BS is not benign at all.

\section{References}

Baddeley, A. D. (1992). Working memory. Science, 255, 556-558.

Barreto, M., \& Ellemers, N. (2005). The burden of benevolent sexism: how it contributes to the maintenance of gender inequalities. European Journal of Social Psychology, 35, 633-642.

Cose, E. (1993). Race as a privileged class. New York: Harper Collins.

Dardenne, B., Delacollette, N., Grégoire, C., \& Lecocq, D. (2006). Latent structure of the French validation of the Ambivalent Sexism Inventory: 1'Echelle de Sexisme Ambivalent. L'Annee Psychologique, 106, 235-264.

Dardenne, B., Dumont, M., \& Bollier, T. (2007). Insidious dangers of benevolent sexism: consequences for women's performance. Journal of Personality and Social Psychology, 93, 764-779.

Dumont, M., \& Dardenne, B. (2008). Lessening women's readiness to accept the status quo helps avoiding benevolent sexism's deleterious impact on performance. (in press). 
Eagly, A. H., \& Mladinic, A. (1989). Gender stereotypes and attitudes toward women and men. Personality and Social Psychology Bulletin, 15, 543-558.

Eagly, A. H., \& Mladinic, A. (1993). Are people prejudiced against women? Some answers from research an attitudes, gender stereotypes, and judgment of competence. In W. Stroebe \& M. Hewstone (Eds.), European review of social psychology (pp. 135). New York: Wiley.

Fiske, S. T., Cuddy, A. J., Glick, P., \& Xu, J. (2002). A model of (often mixed) stereotype content: competence and warmth respectively follow from the perceived status and competition. Journal of Personality and Social Psychology, 82, 878-902.

Fiske, S. T., Cuddy, A. J. C., \& Glick, P. (2007). Universal dimensions of social perception: warmth, then competence. Trends in Cognitive Sciences, 11, 77-83.

Glick, P., \& Fiske, S. T. (1996). The Ambivalent Sexism Inventory: differentiating hostile and benevolent sexism. Journal of Personality and Social Psychology, 70, 491-512.

Glick, P., \& Fiske, S. T. (2001). An ambivalent alliance: hostile and benevolent sexism as complementary justifications for gender inequality. The American Psychologist, 56, 109-118.

Glick, P., Diebold, J., Bailey-Werner, B., \& Zhu, L. (1997). The two faces of Adam: ambivalent sexism and polarized attitudes toward women. Personality and Social Psychology Bulletin, 23, 1323-1334.

Glick, P., Fiske, S. T., Mladinic, A., Saiz, J., Abrams, D., Masser, B., et al. (2000). Beyond prejudice as simple antipathy: hostile and benevolent sexism across cultures. Journal of Personality and Social Psychology, 79, 763-775.

Haines, E. L., \& Jost, J. T. (2000). Placating the powerless: effects of legitimate and illegitimate explanation on affect, memory, and stereotyping. Social Justice Research, 13, 219-236.

Jackman, M. (1994). The Velvet Glove: paternalism and conflict in gender, class and race relations. Berkeley: University of California Press.

Jost, J. T., \& Banaji, M. (1994). The role of stereotyping in system justification and the production of false consciousness. The British Journal of Social Psychology, 22, 1-27.
Jost, J. T., \& Kay, A. C. (2005). Exposure to benevolent sexism and complementary gender stereotypes: consequences for specific and diffuse forms of system justification. Journal of Personality and Social Psychology, 88, 498-509.

Judd, C. M., James-Hawkins, L., Yzerbyt, V. Y., \& Kashima, Y. (2005). Fundamental dimensions of social judgment: understanding the relations between judgments of competence and warmth. Journal of Personality and Social Psychology, 89, 899-913.

Kervyn, N., Yzerbyt, V. Y., Judd, C. M., \& Nunes, A. (2009). A question of compensation: the social life of the fundamental dimensions of social perception. Journal of Personality and Social Psychology (in press).

Moya, M., Glick, P., Exposito, F., de Lemus, S., \& Hart, J. (2007). It's for your own good: benevolent sexism and women's reactions to protectively justified restrictions. Personality and Social Psychology Bulletin, 33, 1421-1434.

Robinson, J. A. (1992). First experience memories: context and functions in personal histories. In M. A. Conway, D. C. Rubin, H. Spinnler, \& W. A. Wagenaar (Eds.), Theoretical perspective on autobiographical memory (pp. 223-239). Dordrecht: Kluwer.

Rudman, L. A., \& Heppen, J. B. (2003). Implicit romantic fantasies and women's interest in personal power: a glass slipper effect. Personality and Social Psychology Bulletin, 29, 1357-1370.

Sidanius, J., \& Pratto, F. (1999). Social dominance: an intergroup theory of social hierarchy and oppression. Cambridge: Cambridge University Press.

Wegner, D. M., \& Erber, R. (1992). The hyperaccessibility of suppressed thoughts. Journal of Personality and Social Psychology, 63, 903-912.

Wegner, D. M., Schneider, D. J., Carter, S. R., \& White, T. L. (1987). Paradoxical effects of thought suppression. Journal of Personality and Social Psychology, 53, 5-13.

Yzerbyt, V. Y., Kervyn, N., \& Judd, C. M. (2008). Compensation versus halo: the unique relations between the fundamental dimensions of social judgment. Personality and Social Psychology Bulletin, 34, 1110-1123. 